TX, United States of America; ${ }^{3}$ Pfizer Japan Inc, Inflammation and Immunology, Tokyo, Japan; ${ }^{4}$ Pfizer Inc, Inflammation and Immunology, Collegeville, PA, United States of America; ${ }^{5}$ Pfizer SLU, Inflammation and Immunology, Madrid, Spain; ${ }^{6}$ Medical University of Vienna, Department of Rheumatology, Vienna, Austria

Background: ORAL Shift, a global Phase $3 \mathrm{~b} / 4$ non-inferiority study, demonstrated sustained efficacy and safety of tofacitinib modified-release (MR) $11 \mathrm{mg}$ once daily (QD) following methotrexate (MTX) withdrawal in patients with rheumatoid arthritis (RA) who achieved Clinical Disease Activity Index (CDAl) low disease activity (LDA) after treatment with tofacitinib + MTX.

Objectives: To assess predictors of durable clinical response in patients receiving tofacitinib MR $11 \mathrm{mg}$ QD in ORAL Shift.

Methods: ORAL Shift (NCT02831855) enrolled patients aged $\geq 18$ years with moderate to severe RA and an inadequate response to MTX. Patients received open-label tofacitinib MR $11 \mathrm{mg}$ QD + MTX for 24 weeks. Patients achieving LDA (CDAl score $\leq 10$ ) at Week (W)24 entered the 24-week double-blind MTX withdrawal phase and were randomised 1:1 to receive tofacitinib MR $11 \mathrm{mg} Q D+$ placebo (tofacitinib monotherapy; ie blinded MTX withdrawal) or continue tofacitinib + MTX. In this post hoc analysis of randomised patients, we assessed predictors of durable response (maintenance of response from W24-48) per CDAI LDA and remission (CDAl score $\leq 2.8$ ) criteria. All covariates were initially assessed for significance in a univariate logistic regression. Highly correlated covariates were reviewed to assess which would be removed prior to modelling in a multivariable logistic regression. Remaining significant $(p \leq 0.10)$ covariates in the univariate regression were selected in the model using a stepwise selection process with $p \leq 0.15$ entry and $p \leq 0.05$ stay criteria. From the final model, estimated odds ratios (ORs) with $95 \%$ confidence intervals (Cls) are presented.

Results: In the double-blind phase of ORAL Shift, durable CDAI LDA and remission rates were: $66.2 \%$ and $14.7 \%$, respectively, with tofacitinib + MTX ( $\mathrm{N}=266)$; and $55.3 \%$ and $11.0 \%$, respectively, with tofacitinib + placebo $(\mathrm{N}=264)$ (Table 1$)$. In the multivariable analysis, five patient covariates significantly predicted durable CDAI LDA (Figure 1; discussed hereafter). Each unit increase in CDAI score at W24 reduced the likelihood of maintaining CDAI LDA by $22.0 \%$. Each unit increase in C-reactive protein (CRP) at W24 increased the likelihood of maintaining CDAI LDA by $4.0 \%$; this may have been due to imbalanced CRP levels at W24 (randomisation) between treatment groups (Figure 1, footnote $\mathrm{C}$ ). The odds of durable CDAI LDA were $53.0 \%$ lower in the US vs Europe and $61.0 \%$ lower in the US vs 'other' regions. Each unit increase in baseline Health Assessment Questionnaire-Disability Index (HAQ-DI) score reduced the odds of durable CDAI LDA by $34.0 \%$. Patients receiving tofacitinib + MTX had $66.0 \%$ greater odds of durable CDAI LDA vs patients receiving tofacitinib + placebo. CDAI at W24 was the only significant predictor of durable CDAI remission in the multivariable analysis: $\mathrm{OR}(95 \% \mathrm{Cl}) 0.32(0.24,0.43)$; $\mathrm{p}<0.0001$. Each unit increase in CDAl score at W24 reduced the odds of durable CDAl remission by $68.0 \%$.

Table 1. Durable CDAI LDA and remission ${ }^{\mathrm{a}}$ in patients receiving tofacitinib MR $11 \mathrm{mg}$ QD with MTX or placebo in the double-blind phase of ORAL Shift

\begin{tabular}{lcc}
\hline & $\begin{array}{c}\text { Tofacitinib + MTX } \\
(\mathbf{N}=\mathbf{2 6 6 )}\end{array}$ & $\begin{array}{c}\text { Tofacitinib + placebo } \\
\mathbf{( N = 2 6 4 )}\end{array}$ \\
\hline Durable CDAI LDA, $\mathrm{n}(\%)$ & $176(66.2)$ & $146(55.3)$ \\
Durable CDAI remission, $\mathrm{n}(\%)$ & $39(14.7)$ & $29(11.0)$
\end{tabular}

aDurable CDAI LDA or remission was defined as achievement of LDA (CDAI score $\leq 10$ ) or remission (CDAl score $\leq 2.8$ ), respectively, at W24-48

$\mathrm{N}$, number of patients in each group; $n$, number of patients achieving outcome
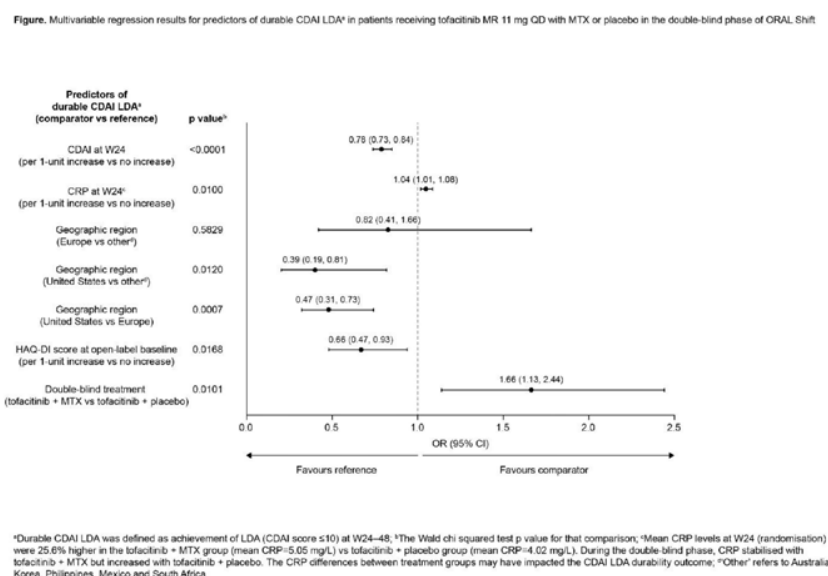

Conclusion: This post hoc analysis of data from ORAL Shift found that CDAI and CRP at W24, geographic region, baseline HAQ-DI and treatment could be predictors for durable CDAI LDA. As these findings were limited to patients who achieved CDAI LDA at W24 with tofacitinib MR $11 \mathrm{mg}$ QD + MTX, additional data in the general patient population need to be investigated. REFERENCES:

[1] Cohen et al. Lancet Rheumatol 2019; 1: E23-34.

Acknowledgements: Study sponsored by Pfizer Inc. Medical writing support was provided by Sarah Piggott, CMC Connect, and funded by Pfizer Inc.

Disclosure of Interests: Kunihiro Yamaoka Speakers bureau: Actelion, Astellas, Chugai, Eisai, Eli Lilly, GlaxoSmithKline, Janssen, Mitsubishi Tanabe, Nippon Shinyaku, Pfizer Inc, Takeda, Consultant of: Actelion, Astellas, Chugai, Eisai, El Lilly, GlaxoSmithKline, Janssen, Mitsubishi Tanabe, Nippon Shinyaku, Pfizer Inc Takeda, Stanley B. Cohen Consultant of: AbbVie, Eli Lilly, Genentech, Gilead Sciences, Pfizer Inc, Grant/research support from: AbbVie, Eli Lilly, Genentech, Gilead Sciences, Pfizer Inc, Naonobu Sugiyama Shareholder of: Pfizer Inc Employee of: Pfizer Inc, Harry Shi Shareholder of: Pfizer Inc, Employee of: Pfize Inc, Jose Luis Rivas Shareholder of: Pfizer Inc, Employee of: Pfizer Inc, Annette Diehl Shareholder of: Pfizer Inc, Employee of: Pfizer Inc, Josef S. Smolen Consultant of: AbbVie, AstraZeneca, Celgene, Celltrion, Chugai, Eli Lilly, Gilead Sciences, ILTOO, Janssen, Novartis-Sandoz, Pfizer Inc, Roche, Samsung Sanofi, Grant/research support from: AbbVie and AstraZeneca DOI: 10.1136/annrheumdis-2021-eular.357

\section{POS0651 CLINICAL AND FUNCTIONAL RESPONSE TO TOFACITINIB IN PATIENTS WITH RHEUMATOID ARTHRITIS: PROBABILITY PLOT ANALYSIS OF RESULTS FROM A 48-WEEK PHASE 3B/4 METHOTREXATE WITHDRAWAL STUDY}

S. B. Cohen ${ }^{1}$, Y. H. Chen ${ }^{2}$, N. Sugiyama ${ }^{3}$, J. L. Rivas ${ }^{4}$, A. Diehl ${ }^{5}$, T. Lukic ${ }^{6}$, J. Paulissen ${ }^{6}$, H. Fan ${ }^{5}$, T. Hirose ${ }^{3}$, E. Keystone $e^{7}{ }^{1}$ Metroplex Clinical Research Center, Dallas, TX, United States of America; ${ }^{2}$ Taichung Veterans General Hospital, Division of Allergy, Immunology, and Rheumatology, Taichung, Taiwan, Republic of China; ${ }^{3}$ Pfizer Japan Inc, Inflammation and Immunology, Tokyo, Japan: ${ }^{4}$ Pfizer SLU, Inflammation and Immunology, Madrid, Spain; ${ }^{5}$ Pfizer Inc, Inflammation and Immunology, Collegeville, PA, United States of America; ${ }^{6}$ Pfizer Inc, Inflammation and Immunology, New York, NY, United States of America; ${ }^{7}$ Mount Sinai Hospital, Toronto, ON, Canada

Background: The Phase 3b/4 study ORAL Shift (NCT02831855) demonstrated sustained efficacy/safety of tofacitinib modified-release $11 \mathrm{mg}$ QD following MTX withdrawal, that was non-inferior to continued tofacitinib + MTX use, in patients (pts) with moderate to severe RA who achieved LDA with tofacitinib + MTX at Week (W) $24 .^{1}$

Objectives: To assess differences and similarities in clinical/functional responses in pts receiving tofacitinib \pm MTX in ORAL Shift.

Methods: In ORAL Shift, pts received open-label tofacitinib + MTX to W24 at W24, pts who achieved CDAI LDA were randomised to receive tofacitinib + MTX or tofacitinib + placebo (PBO) from W24-48. In this post hoc analysis, clinical efficacy endpoints were ACR-N (minimum \% change from baseline $[\mathrm{BL} ; \Delta]$ at W48 achieved by each pt in 3 efficacy measures), $\triangle \mathrm{DAS} 28-4(\mathrm{ESR})$ and DAS28-4(ESR) remission/LDA (scores $\leq 3.2$ ) and moderate/high disease activity (scores >3.2). Functional efficacy endpoints were $\triangle H A Q-D$ and HAQ-DI clinically relevant functional progression (CRFP) status at W48, defined as failure to achieve improvement in $\mathrm{HAQ}-\mathrm{DI} \geq$ minimum clinically important difference (MCID; $\geq 0.22$ decrease from $B L$ in $H A Q-D I)$. Thus, CRFP was defined as $<0.22$ decrease, no change or increase from $B L$ in HAQ-DI at W48. All efficacy endpoints were summarised descriptively. Cumulative probability plots of ACR-N and $\triangle \mathrm{HAQ}-\mathrm{DI}$ were produced. Median of mean CRP values from BL-W24 and >W24-48 were assessed by response subgroups.

Results: 266 pts receiving tofacitinib + MTX and 264 pts receiving tofacitinib + PBO in W24-48 were included. At W48: mean ACR-N was numerically greater with tofacitinib + MTX vs tofacitinib + PBO (60.8 vs 53.1$)$; mean decrease in $\mathrm{HAQ}$-DI was generally similar between groups (-0.71 vs -0.67$)$; mean decrease in DAS28-4(ESR) was numerically greater with tofacitinib + MTX vs tofacitinib + PBO (-2.95 vs -2.68). The differences/similarities between groups in ACR- $N$ and $\triangle \mathrm{HAQ}$-DI were also seen in cumulative probability plots (Figure 1). CRFP rates were numerically lower with tofacitinib + MTX $(18.7 \%)$ vs tofacitinib + PBO $(23.5 \%)$, and in pts with remission/LDA (tofacitinib + MTX, 12.1\%; tofacitinib + PBO, $16.8 \%$ ) vs moderate/high disease activity (tofacitinib + MTX, 26.2\%; tofacitinib + PBO, $30.8 \%$ ). Median of mean CRP over time was generally numerically lower in pts with CRFP vs non-CRFP and DAS28-4(ESR)-defined remission/ LDA vs moderate/high disease activity; and in those receiving tofacitinib + PBO vs tofacitinib + MTX, irrespective of CRFP or DAS28-4(ESR) disease status (Table 1). 
Table 1. Median of mean $\mathrm{CRP}^{\mathrm{a}}$ up to $\mathrm{W} 48$ by response subgroups

\begin{tabular}{|c|c|c|c|c|}
\hline \multirow[b]{2}{*}{$\begin{array}{l}\text { Mean CRP, }{ }^{\mathrm{a}} \text { median } \\
\text { (IQR) }[\mathrm{n}]\end{array}$} & \multicolumn{2}{|c|}{ Tofacitinib $11 \mathrm{mg}$ QD + MTX } & \multicolumn{2}{|c|}{ Tofacitinib 11 mg QD + PBO } \\
\hline & >BL-W24 & $>W 24-48$ & >BL-W24 & $>$ W24-48 \\
\hline HAQ-DI CRFP & $\begin{array}{c}2.84(1.15-7.30) \\
{[45]}\end{array}$ & $\begin{array}{c}2.30(0.82-4.75) \\
{[46]}\end{array}$ & $\begin{array}{c}1.45(0.77-4.42) \\
{[56]}\end{array}$ & $\begin{array}{c}2.28(0.53-7.28) \\
{[56]}\end{array}$ \\
\hline Ion-CRFP & $\begin{array}{c}2.81(1.09-6.19) \\
{[195]}\end{array}$ & $\begin{array}{c}2.91(1.19-5.84) \\
{[195]}\end{array}$ & $\begin{array}{c}2.26(0.98-4.63) \\
{[176]}\end{array}$ & $\begin{array}{c}2.47(1.13-5.53) \\
{[178]}\end{array}$ \\
\hline $\begin{array}{l}\text { DAS28-4(ESR) } \\
\text { remission/LDA }\end{array}$ & $2.48(1.05-4.95)$ & $2.46(1.07-4.76)$ & $1.70(0.89-4.14)$ & $1.95(0.81-3.82)$ \\
\hline $\begin{array}{l}\text { DAS28-4(ESR) moderat } \\
\text { high disease activity }\end{array}$ & [107] & $3.58(1.36-8.33)$ & $2.60(0.87-5.16)$ & $2.68(1.34-8.23)$ \\
\hline
\end{tabular}

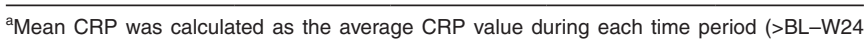
or $>$ W24-48)

CRP, C-reactive protein; DAS28-4(ESR), Disease Activity Score in 28 joints, erythrocyte sedimentation rate; HAQ-DI, Health Assessment Questionnaire-Disability Index; IQR, interquartile range; LDA, low disease activity; MTX, methotrexate; $n$, number of pts meeting assessment criteria; QD, once daily

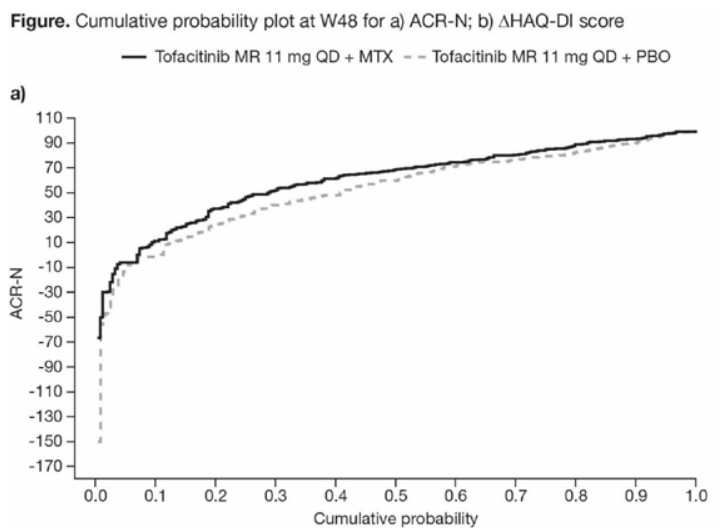

b)

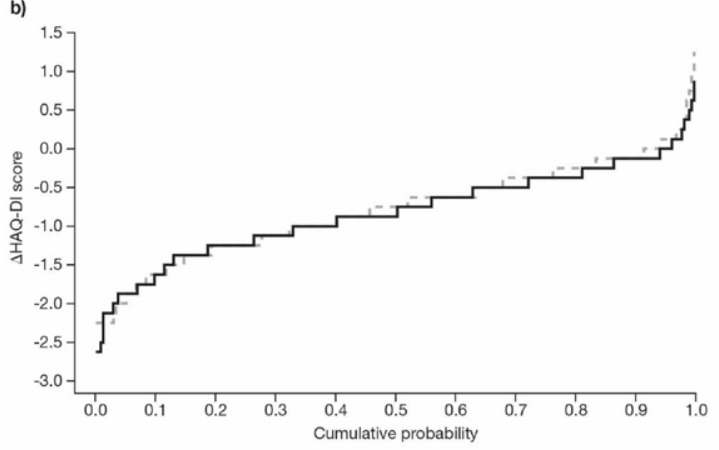

Endpoints were assessed using the full analysis set (defined as all pts receiving $\geq 1$ dose of study drug with $\geq 1$ value post-baseline), with no imputation for missing values

ACR-N, American College of Rheumatology response, where $N$ represents the minimum amount of improvement expressed by each pt in $\% \Delta T$. Assessment; PtGA, Patient Global Assessment; QD, once dally; SJC28, swollen joint count in 28 joints; TJC28, tender joint count in 28 joints

Conclusion: Although clinical/functional responses were generally similar between treatment groups, numerical improvements were seen for some efficacy endpoints with tofacitinib + MTX vs tofacitinib + PBO. A numerically higher CRFP rate may be associated with higher DAS28-4(ESR) disease activity. CRP changes up to W48 may not trend with CRFP status.

REFERENCES:

[1] Cohen et al. Lancet Rheumatol 2019; 1: E23-34.

Acknowledgements: Study sponsored by Pfizer Inc. Medical writing support was provided by Anthony G McCluskey, CMC Connect, and funded by Pfizer Inc. Disclosure of Interests: Stanley B. Cohen Consultant of: AbbVie, Eli Lilly, Genentech, Gilead Sciences, Pfizer Inc, Grant/research support from: AbbVie, Eli Lilly, Genentech, Gilead Sciences, Pfizer Inc, Yi-Hsing Chen Grant/research support from: Bristol-Myers Squibb, GlaxoSmithKline, Pfizer Inc, Naonobu Sugiyama Shareholder of: Pfizer Inc, Employee of: Pfizer Inc, Jose Luis Rivas Shareholder of: Pfizer Inc, Employee of: Pfizer Inc, Annette Diehl Shareholder of: Pfizer Inc, Employee of: Pfizer Inc, Tatjana Lukic Shareholder of: Pfizer Inc, Employee of: Pfizer Inc, Jerome Paulissen Consultant of: Pfizer Inc, Haiyun Fan Shareholder of: Pfizer Inc, Employee of: Pfizer Inc, Tomohiro Hirose Shareholder of: Pfizer Inc, Employee of: Pfizer Inc, Edward Keystone Speakers bureau: AbbVie, Amgen, F. Hoffman-La Roche, Janssen, Merck, Novartis, Pfizer Inc, Sanofi
Genzyme, Consultant of: AbbVie, Amgen, Bristol-Myers Squibb, Celltrion, Eli Lilly, F. Hoffman-La Roche, Gilead Sciences, Janssen, Merck, Myriad Autoimmune, Pfizer Inc, Sandoz, Sanofi Genzyme, Samsung Bioepsis, Grant/research support from: Amgen, Merck, Pfizer Inc, PuraPharm DOI: 10.1136/annrheumdis-2021-eular.358

\section{\begin{tabular}{|l|l}
\hline POS0652 SEX DIFFERENCES IN THE EFFICACY AND SAFETY \\
\hline
\end{tabular} OF TOFACITINIB IN RHEUMATOID ARTHRITIS PATIENTS: A POST HOC ANALYSIS OF PHASE 3 AND LONG-TERM EXTENSION TRIALS}

H. N. Jones ${ }^{1}$, V. Strand ${ }^{2}$, H. Schulze-Koops ${ }^{3}$, E. Mysler ${ }^{4}$, C. Kinch ${ }^{5}$, D.

C. Gruben ${ }^{6}$, R. Germino ${ }^{7}$, C. A. Connell ${ }^{8}$, L. Eder ${ }^{9}{ }^{1}$ University of Alberta, Division of Rheumatology, Edmonton, AB, Canada; ${ }^{2}$ Stanford University, Division of Immunology/Rheumatology, Palo Alto, CA, United States of America; ${ }^{3}$ University of Munich, Division of Rheumatology and Clinical Immunology, Department of Internal Medicine IV, Munich, Germany; ${ }^{4}$ Organización Médica de Investigación, Buenos Aires, Argentina; ${ }^{5}$ Pfizer Canada ULC, Inflammation and Immunology, Kirkland, QC, Canada; ${ }^{6}$ Pfizer Inc, Inflammation and Immunology, Groton, CT, United States of America; ${ }^{7}$ Pfizer Inc, Inflammation and Immunology, New York, NY, United States of America; ${ }^{8}$ Pfizer Inc, Clinical Development and Operations, Groton, CT, United States of America; ${ }^{9}$ University of Toronto, Women's College Research Institute, Department of Medicine, Toronto, ON, Canada

Background: Differences in efficacy outcomes favouring males vs females with rheumatoid arthritis (RA) have been reported with conventional synthetic (cS) disease-modifying antirheumatic drugs (DMARDs) and tumour necrosis factor inhibitors; results with Janus kinase inhibitors are less clear.

Objectives: To assess the impact of sex on efficacy, safety and persistence in tofacitinib RA clinical trials.

Methods: Efficacy and safety analyses included data pooled from Phase $(P) 3$ randomised controlled trials (RCTs) of patients (pts) with RA and an inadequate response (IR) to methotrexate (NCT00847613; NCT00853385) or $\geq 1$ DMARD (NCT00856544) who received tofacitinib 5 or $10 \mathrm{mg}$ twice daily (BID), adalimumab (ADA) $40 \mathrm{mg}$ Q2W or placebo (PBO), with background csDMARDs. Persistence analyses of pts receiving tofacitinib 5 or $10 \mathrm{mg} \mathrm{BID} \pm$ csDMARDs used data pooled from two long-term extension trials (NCT00661661; NCT00413699). Efficacy outcomes to Month (M)12 included: ACR20/50/70 responses, changes from baseline $(\Delta ; \mathrm{BL})$ in DAS28-4(ESR), CDAI, HAQ-DI and FACIT-F, and DAS284(ESR) remission (<2.6). Safety was evaluated to M24 for tofacitinib and ADA. Kaplan-Meier persistence analysis estimated time to discontinuation.

Results: 2265 pts were included from P3 RCTs. Demographics and BL characteristics were comparable across sexes and treatments. Tofacitinib or ADA vs PBO generally led to significantly higher ACR20/50/70 responses in both sexes through M6. To M12, ACR20/50/70 responses were broadly comparable across active treatments and between sexes, with significant differences favouring males at some time points, including M3 (Figure 1). Statistically significant differences favouring males vs females were observed in DAS28-4(ESR) remission rates at most time points, including M3 (Figure 1); a similar trend was observed for $\triangle \mathrm{DAS} 28-4(\mathrm{ESR})$ $\triangle \mathrm{CDAl}, \triangle \mathrm{HAQ}-\mathrm{DI}$ and $\triangle \mathrm{FAClT}-\mathrm{F}$ significantly favoured males vs females receiving tofacitinib $5 \mathrm{mg}$ BID at most time points, while $\triangle \mathrm{HAQ}-\mathrm{DI}$ and $\triangle \mathrm{FACIT}-\mathrm{F}$ tended to favour females receiving tofacitinib $10 \mathrm{mg} B I D$. Rates of adverse events (AEs), serious AEs (SAEs), severe AEs and discontinuations due to AEs were slightly higher in females vs males with tofacitinib $5 \mathrm{mg} \mathrm{BID}$; this was generally reversed with tofacitinib $10 \mathrm{mg} \mathrm{BID}$ and ADA (Table 1). AEs of special interest (AESI) were comparable between sexes with tofacitinib and ADA, although low event numbers limit interpretation (Table 1). Time to all-cause discontinuation and discontinuation due to $\mathrm{AEs} /$ lack of efficacy with tofacitinib $5 \mathrm{mg}$ BID was similar between sexes. Numerical differences favouring females vs males were observed for time to all-cause discontinuation and discontinuation due to AEs with tofacitinib $10 \mathrm{mg} \mathrm{BID}$.

Table 1. Safety summary to M24 in pooled DMARD-IR P3 RCTs

\begin{tabular}{|c|c|c|c|c|c|c|}
\hline \multirow[b]{2}{*}{$\begin{array}{l}\text { Pts with events, } \\
\text { n (\%) }\end{array}$} & \multicolumn{2}{|c|}{$\begin{array}{l}\text { Tofacitinib } \\
5 \mathrm{mg} \text { BID }\end{array}$} & \multicolumn{2}{|c|}{$\begin{array}{l}\text { Tofacitinib } \\
10 \mathrm{mg} \text { BID }\end{array}$} & \multicolumn{2}{|c|}{ ADA } \\
\hline & $\begin{array}{l}\text { Females } \\
(\mathrm{N}=707)\end{array}$ & $\begin{array}{c}\text { Males } \\
(\mathrm{N}=133)\end{array}$ & $\begin{array}{l}\text { Females } \\
(\mathrm{N}=698)\end{array}$ & $\begin{array}{l}\text { Males } \\
(\mathrm{N}=137)\end{array}$ & $\begin{array}{c}\text { Females } \\
(\mathrm{N}=162)\end{array}$ & $\begin{array}{l}\text { Males } \\
(\mathrm{N}=42)\end{array}$ \\
\hline AEs & $562(79.5)$ & $85(63.9)$ & $529(75.8)$ & $107(78.1)$ & $119(73.5)$ & $30(71.4)$ \\
\hline SAEs & $107(15.1)$ & $17(12.8)$ & $71(10.2)$ & $24(17.5)$ & $13(8.0)$ & $6(14.3)$ \\
\hline Severe AEs & $86(12.2)$ & $12(9.0)$ & $55(7.9)$ & $22(16.1)$ & $14(8.6)$ & $5(11.9)$ \\
\hline Discontinuations due to $\mathrm{AEs}$ & 87 (12.3) & $10(7.5)$ & $88(12.6)$ & $10(7.3)$ & $17(10.5)$ & $5(11.9)$ \\
\hline $\begin{array}{l}\text { Death } \\
\text { AESI }\end{array}$ & $6(0.8)$ & $4(3.0)$ & 0 & $3(2.2)$ & $1(0.6)$ & $2(4.8)$ \\
\hline Serious infections & $28(4.0)$ & $6(4.5)$ & 27 (3.9) & $6(4.4)$ & $2(1.2)$ & $1(2.4)$ \\
\hline All HZ (non-serious/serious) & $35(5.0)$ & $7(5.3)$ & $43(6.2)$ & $5(3.6)$ & $2(1.2)$ & $3(7.1)$ \\
\hline MACE & $5(0.7)$ & 0 & $2(0.3)$ & $3(2.2)$ & 0 & $3(7.1)$ \\
\hline Malignancies (excl. NMSC) & $7(1.0)$ & $1(0.8)$ & $9(1.3)$ & $1(0.7)$ & 0 & $1(2.4)$ \\
\hline NMSC & $2(0.3)$ & $5(3.8)$ & $4(0.6)$ & $2(1.5)$ & $1(0.6)$ & $1(2.4)$ \\
\hline Venous thromboembolism & $3(0.4)$ & 0 & $3(0.4)$ & $1(0.7)$ & 0 & 0 \\
\hline
\end{tabular}

$\mathrm{HZ}$, herpes zoster; MACE, major adverse cardiovascular events; NMSC, non-melanoma skin cancer 